\title{
Mechanical Properties of Counter-gravity Cast IN718
}

\author{
Sanjay Shendye ${ }^{1}$, Blair King ${ }^{1}$ and Paul McQuay ${ }^{2}$ \\ ${ }^{1}$ Metal Casting Technology, Inc., 127 Old Wilton Road, Milford, NH 03055 \\ ${ }^{2}$ Hitchiner Manufacturing Co., Inc., Milford, NH 03055
}

Key Words: Counter-gravity, investment casting, superalloys, IN718, inert atmosphere

\begin{abstract}
Three molds consisting of 36 test-bar blanks each and test coupons were cast in IN718, a Ni-base alloy, using the Counter-gravity Low-pressure Inert-atmosphere (CLI) investment casting process. Test coupons were analyzed for chemical composition and the test bar blanks machined and tested for tensile and stress rupture properties. Larsen-Miller parameter was calculated from the stress rupture test data. Stress levels ranged from 70 to $130 \mathrm{ksi}$ and the temperature ranged from $1000{ }^{\circ} \mathrm{F}$ to $1300{ }^{\circ} \mathrm{F}$ for the stress rupture test. Fracture surfaces and microstructure of the test bars was evaluated using optical and scanning electron microscopy techniques.

Chemical composition of the alloy was found to be relatively stable and within the specification limits. A slightly higher oxygen content was observed as compared with the vacuum induction melted and gravity-cast IN718. This however, did not adversely affect the tensile or the stress rupture properties. The experimentally determined Larson-Miller parameter was found to be comparable to that published in the literature. Grain size ranging from 0.010 " to 0.060 " was observed. No notable defects were identified by non-destructive X-ray and fluorescent penetrant inspections (FPI), or by microstructure and fractographic evaluations.
\end{abstract}

The CLI casting process is an investment casting process developed by Metal Casting Technology, Inc., and patented by Hitchiner Manufacturing Co., Inc. CLI-casting trials for IN718 aerospace components are in progress, while several components are currently in production using the CLI process in other Nibase superalloys such as IN713C, Haynes 230, Nimonic 90. Some of these applications and the specific advantages of CLI casting for these applications are reviewed.

\section{Introduction}

Investment casting of Ni-based alloys involves vacuum induction melting (VIM) the alloy and gravity assisted pouring the molten alloy into ceramic molds in a vacuum atmosphere $[1,2]$. In the CLI casting process, the alloy is melted in a refractory crucible in an inert argon atmosphere as opposed to vacuum, and the alloy is filled into the mold from the bottom by creating a vacuum in the mold cavity. Outlined in Figure 1 is the principle of the CLI melting and casting process.

In the CLI process, as soon as the molten alloy is ready to be cast, a preheated ceramic tube is placed on the bottom opening of a mold chamber. A preheated ceramic mold is transferred into the chamber and placed on top of the ceramic tube. Support media is packed around the preheated mold and the chamber containing the mold is transferred to the melting furnace. The tube at the bottom of the chamber is then 
inserted into the argon atmosphere above the molten alloy. Argon is drawn into to the mold chamber by creating a vacuum in the mold. This action essentially displaces air in the mold cavity through the semiporous mold with argon. The tube is then inserted deep into the molten alloy and the vacuum in the mold cavity is increased at a controlled rate, enabling the mold filling. The level of vacuum in the mold cavity depends upon the alloy to be cast and the total height of the mold. Typically a low level of vacuum (1/3 of an atmosphere) is sufficient to fill the mold in 2 to 5 seconds.

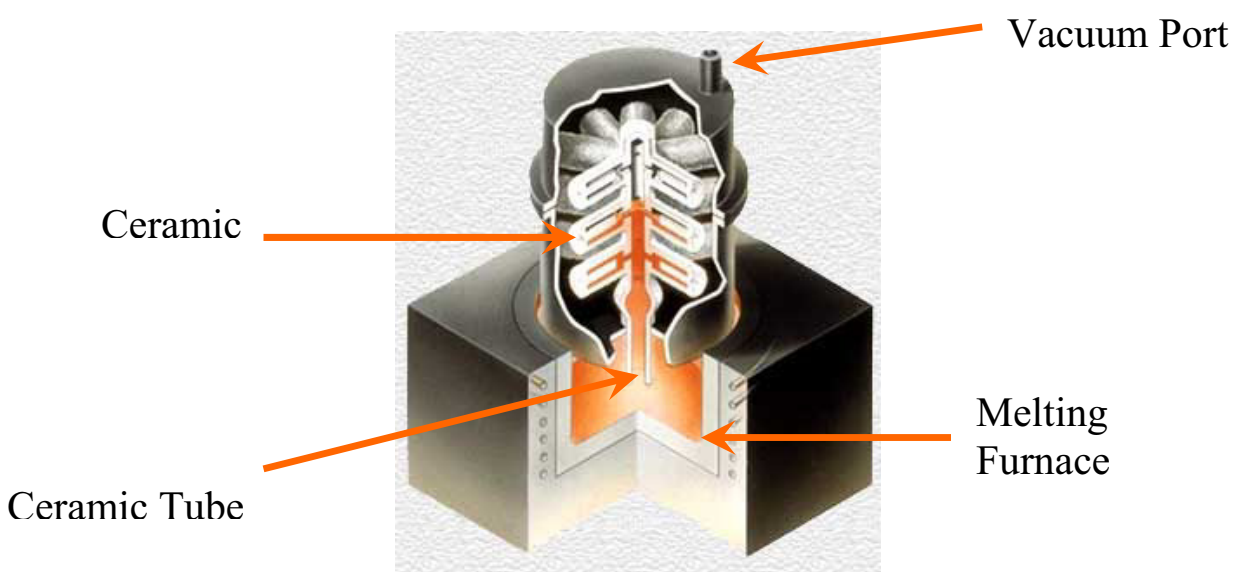

Figure 1: Schematic illustration of the CLI melting and casting process. Support media packed around the mold is not shown in this illustration for the purpose of clarity.

After the mold is completely filled, it is held under vacuum for a specific amount of time that depends on parameters such as the alloy, wall thickness of the castings, mold temperature prior to cast, alloy temperature, etc. During this time interval, the ceramic tube is kept immersed into the molten alloy and the castings with in-gates are solidified. At the end of the mold fill cycle, the vacuum on the mold chamber returning it to atmospheric pressure, which returns the molten alloy in the mold center sprue back into the crucible. The mold chamber containing the filled mold is lifted up and the ceramic tube is raised above the molten alloy. The mold containing the solidified castings is then dropped into a sand bucket and air-cooled to room temperature. The furnace crucible is then recharged with alloy.

It was a concern that the chemical composition, cleanliness of the alloy and the resulting mechanical properties may be adversely affected by the CLI process. Elements such as Al, Ti and Cr have a high affinity for $\mathrm{O}_{2}$ and $\mathrm{N}_{2}$ within the argon atmosphere, and can form inclusions in the castings [1, 2]. Since a significant amount of liquid alloy is returned to the crucible after each mold is filled, contaminants such as loose refractory material in the mold cavity or the alloy-ceramic snout and/or the alloy-shell material reaction product could enter the melt, and the mold, during the subsequent molds cast. Several studies were undertaken to evaluate the effect of such processing variables on chemical composition, cleanliness of the alloy, and tensile and stress rupture properties for Ni-base alloys such as IN713LC, Haynes 230, Nimonic 90 and IN718. Specifically, tensile and stress rupture properties, and microstructure of CLI-cast IN718 alloy and examples of components cast using the CLI process are discussed in this paper.

\section{Experimental Procedure}

A total of 3 test-bar molds with chemical test coupons and 36 test bar blanks ( $1 / 2$ " dia x 4 " long) per mold were made using the standard investment casting shell making procedures. A single IN718 ingot charge of $120 \mathrm{lb}$. was used as the starting alloy charge. Shown in Table I is the chemical composition of the 
starting material received from a certified ingot supplier. All three molds were cast in succession in approximately 10-minute interval between molds.

Table I: Chemical composition of the starting IN718 alloy ingot.

\begin{tabular}{|l|c|c|c|c|c|c|c|c|c|}
\hline Element & $\mathrm{C}$ & $\mathrm{Cr}$ & $\mathrm{Al}$ & $\mathrm{Mo}$ & $\mathrm{Nb}$ & $\mathrm{Ti}$ & $\mathrm{B}$ & $\mathrm{Zr}$ & $\mathrm{Si}$ \\
\hline $\mathrm{Wt} \%$ & 0.05 & 18.24 & 0.43 & 3.08 & 5.01 & 0.97 & 0.003 & 0.01 & 0.04 \\
\hline
\end{tabular}

Casting conditions such as the mold transfer time, alloy temperature, mold preheat temperature, mold fill rate, and the argon gas flow rate over the molten alloy in the furnace were all held constant. Ceramic dwell time - the time for which the ceramic tube at the bottom of the mold chamber is held in the molten alloy - was also held constant for all the 3 molds. Dross, also called slag, was removed from the molten alloy surface between successive molds cast.

After the molds were cooled to room temperature, chemical test coupons and the test bar blanks were removed from the mold and the test bar blanks inspected by visual inspection, fluorescent penetrant inspection (FPI) and X-ray techniques commonly used in the investment casting industry. After inspection, the chemical test coupons and the test bar blanks from the first and last cast molds were sent to Dirats Laboratories, Westfield, MA for determination of chemical composition and mechanical properties. All the test bars were heat treated per PWA 1469 L specification [3] that involved hot isostatic press (HIP), solution anneal and precipitation hardening. Heat treatment parameters used are shown in Table II. Two test bars each were evaluated for room temperature (RT), $1200{ }^{\circ} \mathrm{F}$ and $1300{ }^{\circ} \mathrm{F}$ tensile properties. Additional test bars were tested for stress rupture (SR) properties per the matrix shown in Table III. Larson-Miller parameter [4,5] was determined using the SR properties data. Test bars were selected from each of the 3 molds for all the mechanical properties tested.

Table II: PWA 1469 L Heat treatment parameters used to heat treat the test bar blanks prior to tensile and SR testing.

\begin{tabular}{|c|l|}
\hline Step & HIP and heat treatment parameters \\
\hline 1 & HIP $2150{ }^{\circ} \mathrm{F}$ to $2200{ }^{\circ} \mathrm{F}$ for $4 \mathrm{hr}$ at $15 \mathrm{ksi}$. \\
\hline 2 & $\begin{array}{l}\text { Stabilization heat treatment }- \text { heat to } 1600{ }^{\circ} \mathrm{F} \text { in protective atmosphere, hold } \\
\text { for } 10 \mathrm{hr} \text {, cool at any rate equivalent to aircool or faster. }\end{array}$ \\
\hline 3 & $\begin{array}{l}\text { Solution heat treatment }- \text { heat to } 1750{ }^{\circ} \mathrm{F} \text { in a protective atmosphere, hold for } 1 \\
\text { hr and cool at a rate equivalent to aircool or faster. }\end{array}$ \\
\hline 4 & $\begin{array}{l}\text { Precipitation heat treatment }- \text { heat to } 1350{ }^{\circ} \mathrm{F}, \text { hold for } 8 \mathrm{hr} \text {, furnace cool at a } \\
\text { rate of } 100{ }^{\circ} \mathrm{F} / \mathrm{hr} \text { to } 1225, \text { hold for } 8 \mathrm{hr} \text { and cool. }\end{array}$ \\
\hline 5 & $\begin{array}{l}\text { Precipitation heat treatment }- \text { heat to } 1400{ }^{\circ} \mathrm{F}, \text { hold for } 5 \mathrm{hr} \text {, furnace cool at a } \\
\text { rate of } 100{ }^{\circ} \mathrm{F} / \mathrm{hr} \text { to } 1200, \text { hold for } 1 \mathrm{hr} \text { and cool. }\end{array}$ \\
\hline
\end{tabular}

Table III: Stress rupture test matrix.

\begin{tabular}{|l|c|l|l|l|}
\hline SR Test & $1000{ }^{\circ} \mathrm{F}$ & $1100^{\circ} \mathrm{F}$ & $1200^{\circ} \mathrm{F}$ & $1300{ }^{\circ} \mathrm{F}$ \\
\hline \# specimens & $\begin{array}{c}1 \text { at each stress } \\
\text { load }\end{array}$ & $\begin{array}{l}1 \text { at each } \\
\text { stress load }\end{array}$ & $\begin{array}{l}1 \text { at each } \\
\text { stress load }\end{array}$ & $\begin{array}{l}1 \text { at each stress } \\
\text { load }\end{array}$ \\
\hline $\begin{array}{l}\text { Test load, } \\
\text { ksi }\end{array}$ & $\begin{array}{c}130,120 \text { and } \\
110\end{array}$ & $\begin{array}{c}130,120 \text { and } \\
115\end{array}$ & $\begin{array}{c}115,110,95 \\
\text { and } 85\end{array}$ & $\begin{array}{c}100,90,80 \text { and } \\
70\end{array}$ \\
\hline
\end{tabular}

One longitudinal and transverse x-section of a fully heat treated test bar blank from each of the 3 molds was sectioned, mounted, polished and etched and examined using the optical microscope and the 
SEM/EDAX unit for grain size, secondary phases, porosity, oxides and inclusions. Fracture surfaces of the RT tensile tested bars were also examined using the scanning electron microscopy (SEM) and energy dispersive spectroscopy (EDS) techniques.

\section{Results}

Shown in Table IV is the chemical composition of the test coupons analyzed. Also shown for comparison purposes is the chemical composition specification of the alloy ingot used for casting all the test bar molds.

Table IV: Chemical composition (wt $\%$ ) of the test coupons. Also shown for reference is the chemical composition of the starting alloy ingot.

\begin{tabular}{|c|c|c|c|c|c|c|c|c|c|c|c|}
\hline & & & & & & & & & & & \\
Mold No. & $\mathrm{C}$ & $\mathrm{Cr}$ & $\mathrm{Al}$ & $\mathrm{Mo}$ & $\mathrm{Nb}$ & $\mathrm{Ti}$ & $\mathrm{B}$ & $\mathrm{Zr}$ & $\mathrm{Si}$ & $\mathrm{N}$ & $\mathrm{O}$ \\
\hline 1 & 0.044 & 18.20 & 0.44 & 3.05 & 4.96 & 0.96 & 0.003 & 0.01 & 0.05 & 0.0049 & 0.0020 \\
\hline 3 & 0.054 & 18.22 & 0.46 & 3.06 & 4.98 & 0.97 & 0.003 & 0.01 & 0.05 & 0.0051 & 0.0013 \\
\hline Starting alloy & 0.050 & 18.24 & 0.43 & 3.08 & 5.01 & 0.97 & 0.003 & 0.01 & 0.04 & & \\
\hline
\end{tabular}

Results of the RT, $1200{ }^{\circ} \mathrm{F}$ and $1300{ }^{\circ} \mathrm{F}$ tensile tests and SR tests are shown in Figure 2. Each data point for the tensile test is an average of 2 test bars, while that for the stress rupture test is a result of one test bar.
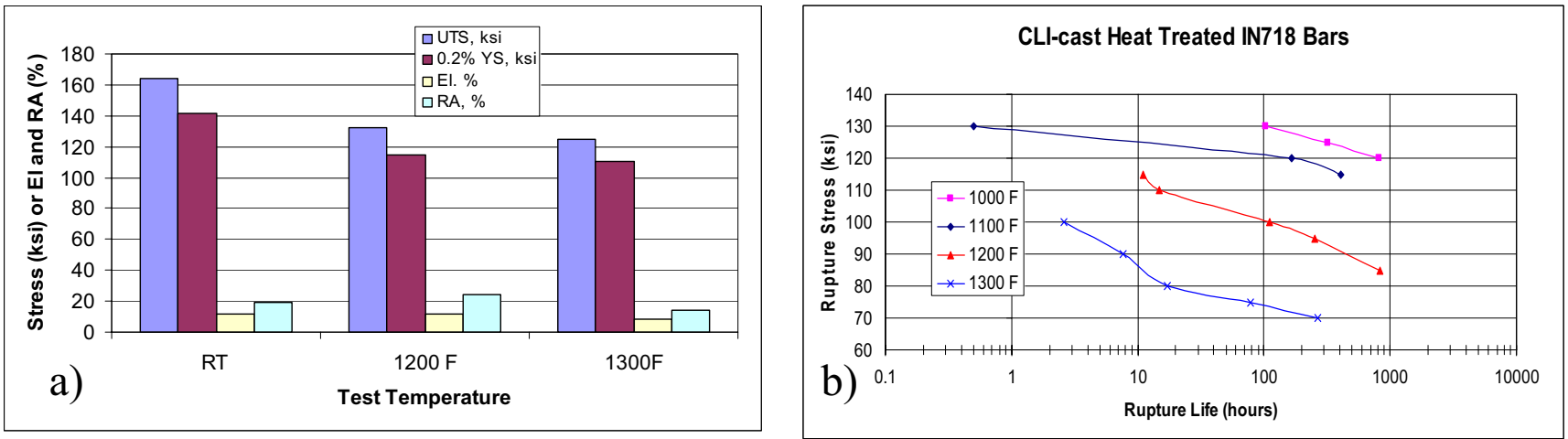

Figure 2: a) Tensile properties of test bars. PWA 1469 specification: @ RT - UTS 155 ksi, 0.2\% YS $120 \mathrm{ksi}$, elongation 6\% and reduction in area 12\%. @ $1200{ }^{\circ} \mathrm{F}$ - UTS $115 \mathrm{ksi}, 0.2 \%$ YS $95 \mathrm{ksi}$, elongation $6 \%$, and reduction in area $12 \%$ b) Stress rupture properties of test bars tested at various temperatures and test loads. PWA 1469 specification: minimum rupture life of $23 \mathrm{hr}$ at a stress of $90 \mathrm{ksi}$ at $1200{ }^{\circ} \mathrm{F}$.

The Larson-Miller (LM) parameter calculated from the SR test data was found to be

$$
\mathrm{P}=0.001 \times \mathrm{T} \times(\log \mathrm{t}+28)
$$

Where $\mathrm{T}=$ test temperature in degrees Rankine $\left({ }^{\circ} \mathrm{R}={ }^{\circ} \mathrm{F}+460\right)$ and $\mathrm{t}=$ rupture time in hours.

The LM parameter was calculated using the methods described in the literature [5]. Shown in Figure 3 is the graph of the SR data plotted using the LM parameter from equation (1) above. A regression analysis was also done for the data that was plotted as shown on the same graph. 


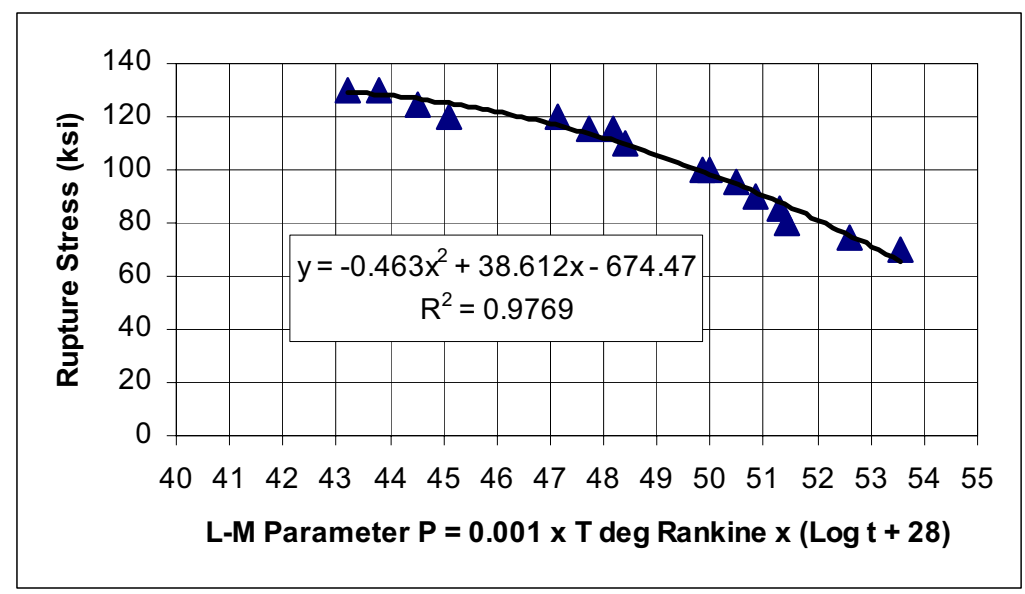

Figure 3: Graph showing the SR data plotted using the calculated LM parameter.

There were no rejectable indications observed in visual inspection, FPI and x-ray evaluation of the test bar blanks.

The fracture surfaces of the RT tensile tested bars were examined using the SEM. There were no observable defects such as shrinkage, oxide and ceramic inclusions on the fracture surface. SEM fractographs of the surface are shown in Figure 4.
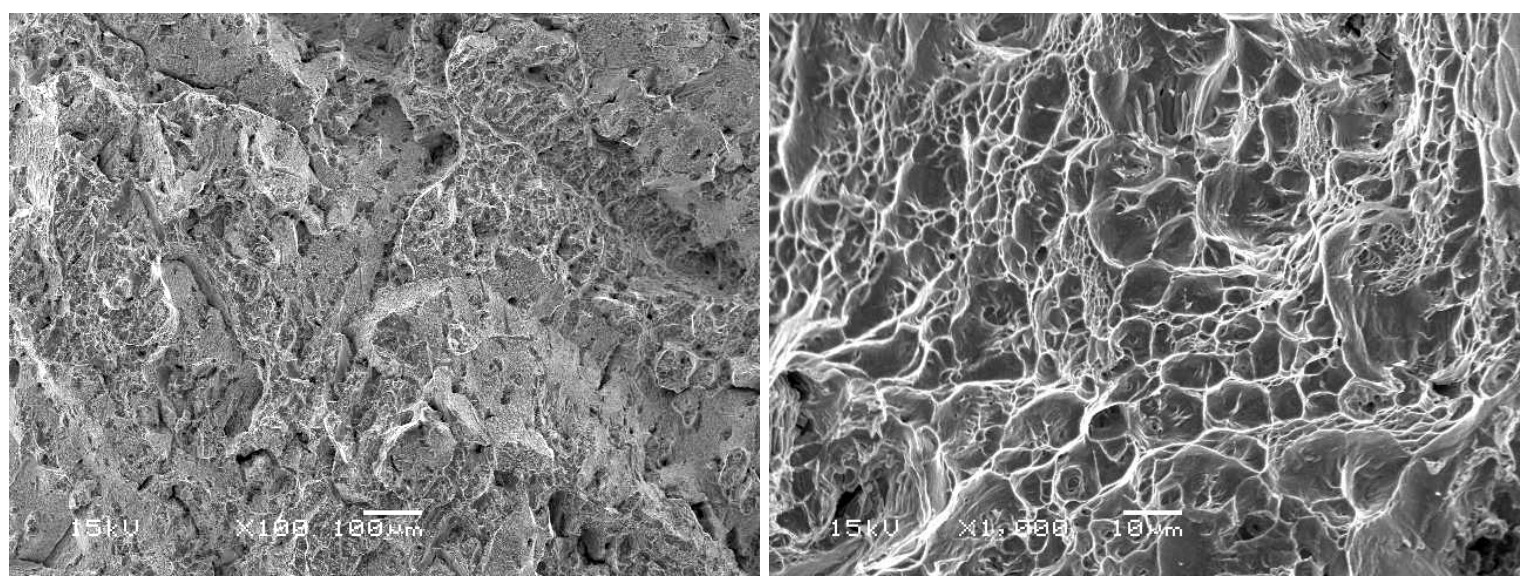

Figure 4: SEM fractographs of the RT tensile tested bars. There were no observable defects such as shrinkage, oxide and ceramic inclusions on the fracture surface.

Shown in Figures 5 and 6 is the typical grain size and the grain boundary and inter-dendritic carbides and borides observed in the microstructure. Typical energy dispersive spectroscopy (EDS) analysis of a $(\mathrm{Nb}, \mathrm{Ti})$ rich carbide/boride particle observed at the grain boundaries and in the inter-dendritic regions is shown in Figure 7. Shown in Figure 8 is the back-scatter SEM electron micrograph of a dark appearing (Al, Ti) oxide/Ti carbo-nitride particle from Figure 6a). In such particles, an Al oxide rich nucleus was surrounded by Ti carbo-nitride rich precipitate. Length of such oxide/carbo-nitride particles was found to be less than $25 \mathrm{um}$, similar to that of the (Nb, Ti) carbide/boride particles. EDS analyses of the dark appearing $\mathrm{Al}$ oxide nucleus and the surrounding Ti carbo-nitride rich precipitate are shown in Figure 9. 

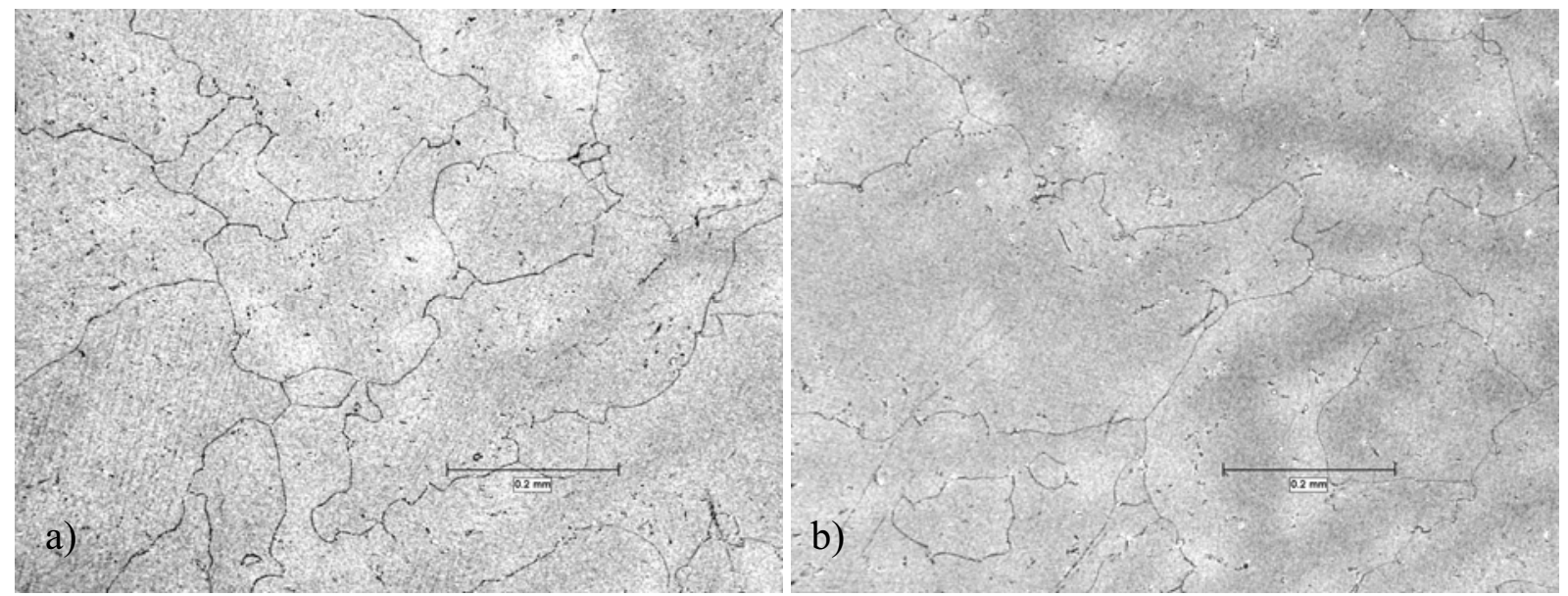

Figure 5a) and 5b): Typical grain structure observed in the microstructure. Grain size was found to vary from $0.010 "$ to $0.060 "$ ".
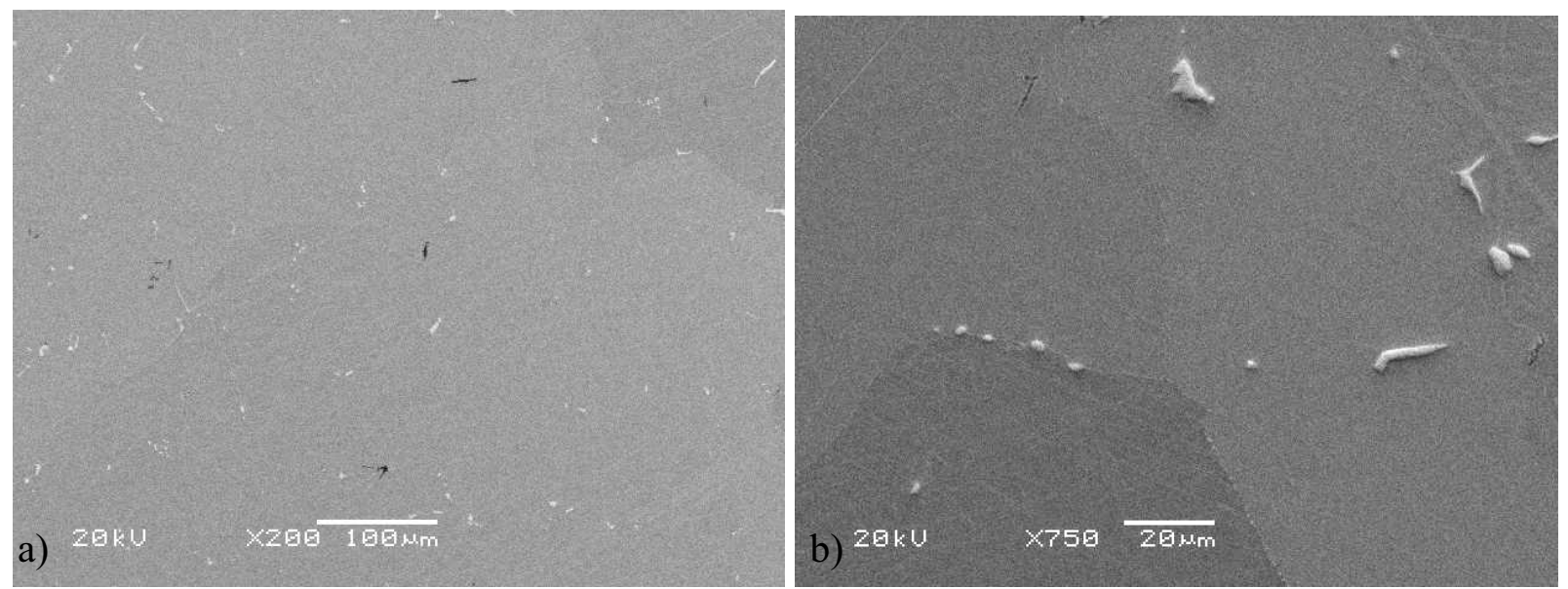

Figure 6a) and 6b): SEM back-scatter electron micrographs showing the bright appearing grain boundary and inter-dendritic carbides and borides less than $25 \mathrm{um}$ in length in the microstructure. The dark appearing particles in figure a) were found to be (Al, Ti) oxide/Ti carbo-nitride. Size of the (Al, Ti) oxide/Ti carbo-nitride particles was the same as that of the carbide/boride particles.

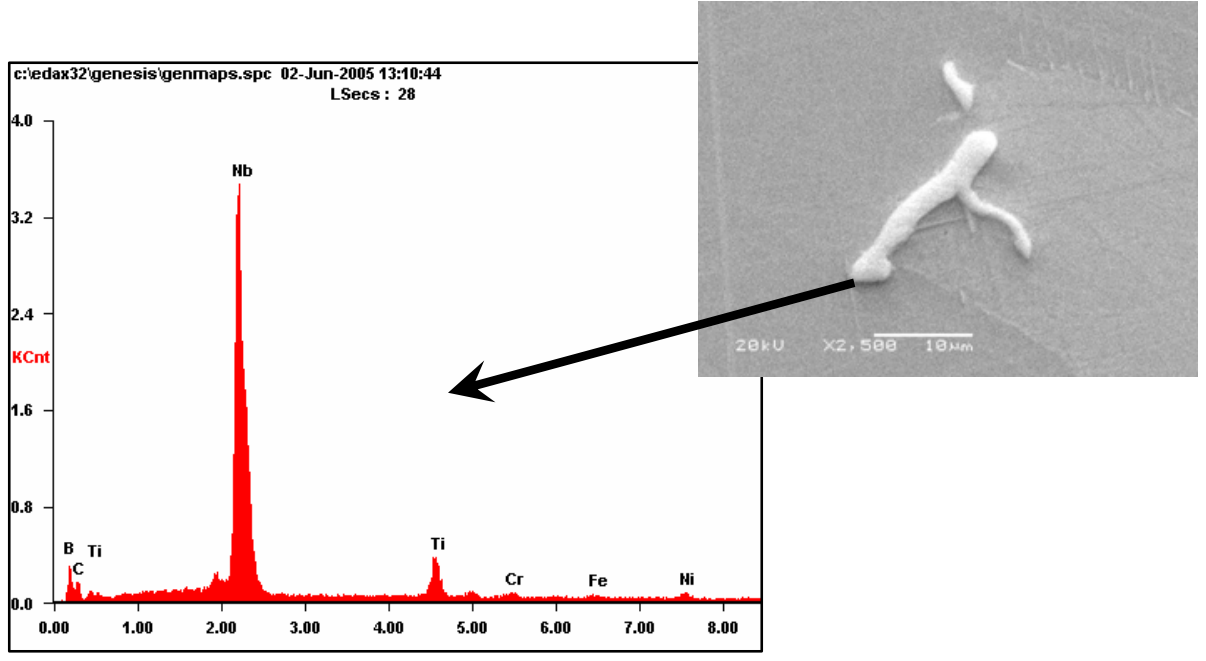

Figure 7: EDS analysis of the $(\mathrm{Nb}, \mathrm{Ti})$ rich carbide/boride in the microstructure. 
Figure 8: Magnified back-scatter electron SEM micrograph of a dark appearing (Al, Ti) oxide/Ti carbonitride precipitate shown in Figure 6a). These particles consisted of an Al oxide rich nucleus surrounded by Ti carbo-nitride precipitate.

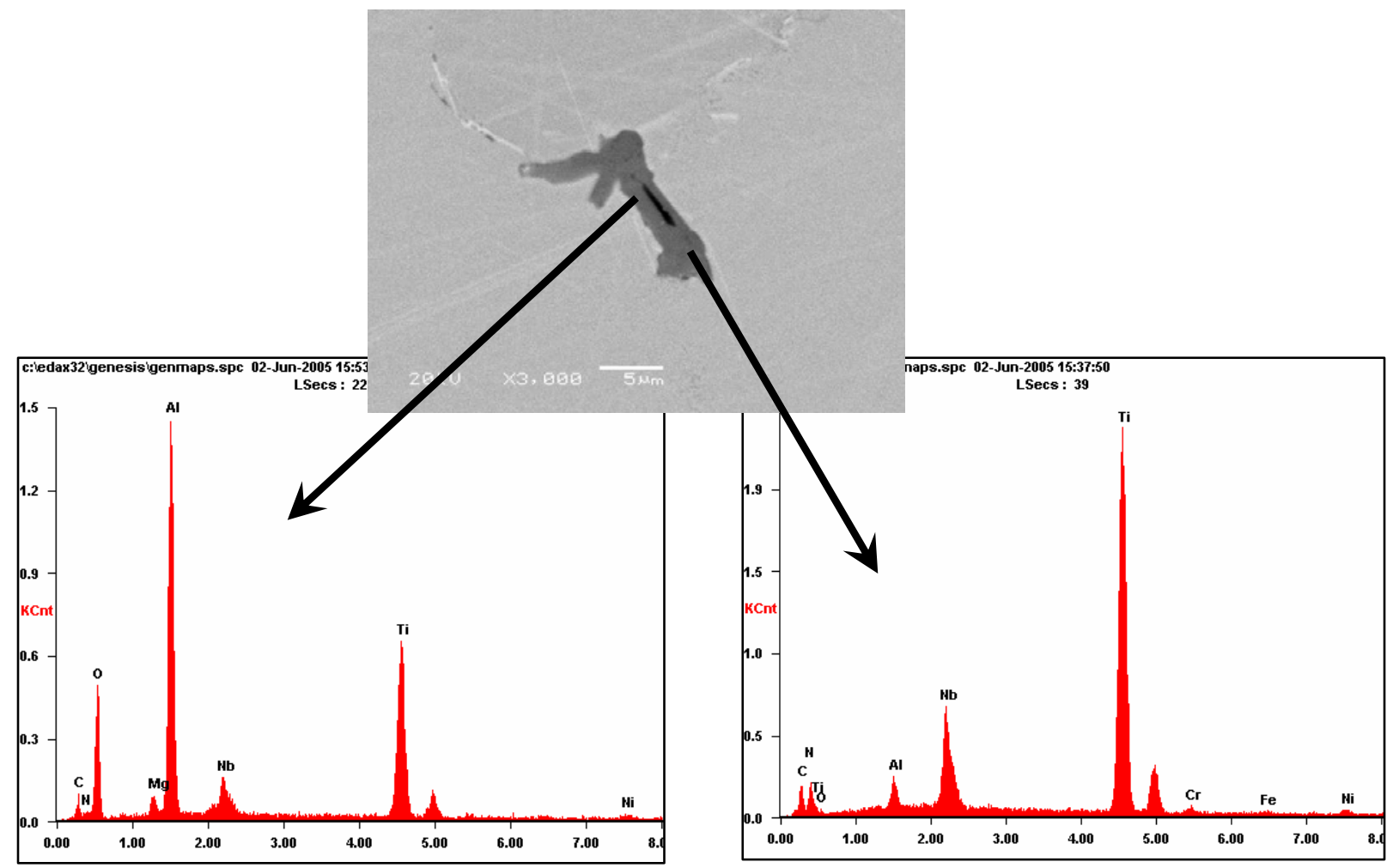

Figure 9: EDS analyses of a dark appearing (Al, Ti) oxide/Ti carbo-nitride particles shown in Figure 6a) and Figure 8.

\section{Discussion}

Many elements in the IN718 alloy composition, such as $\mathrm{Cr}$, Ti and Al have a high affinity for elements such as $\mathrm{O}$ and/or $\mathrm{N}$ and can form oxide and/or nitride inclusions $[1,2,7]$. Such inclusions in the microstructure of a cast component can adversely affect its mechanical properties, specifically loss of ductility, and SR life [6]. In addition, oxygen and nitrogen can also tie up $\mathrm{Cr}$ that promotes the formation of the gamma double prime $\left(\gamma^{\prime}\right)$ phase, which is the primary strengthening phase for IN718 [7]. N can induce micro-porosity and promote deleterious Ti carbo-nitride formation, which can adversely affect 
mechanical properties and weldability [2]. These are the primary reasons why IN718 alloy is typically melted and cast in vacuum.

Typical $\mathrm{O}_{2}$ level in the atmosphere just above the melt during CLI melting, as measured by a probe inserted in the argon atmosphere right above the molten alloy, was found to range from 50 to $100 \mathrm{ppm}$ [8]. This, however, resulted in O pickup in the alloy of only up to $20 \mathrm{ppm}$ as shown in Table IV. Typical elemental concentration of $\mathrm{O}$ and $\mathrm{N}$ in aerospace quality vacuum induction melted (VIM) and vacuum cast IN718 is $60 \mathrm{ppm} \mathrm{N}$ and $<5$ ppm O $[2,6]$. The $\mathrm{N}$ concentration of the CLI-cast alloy was thus comparable to that of the vacuum induction melted and vacuum cast IN718, while the $\mathrm{O}$ concentration was slightly higher (Table IV). Although $\mathrm{N}_{2}$ content in the atmosphere above the CLI melt was not measured, it is likely that it was higher than levels normally encountered in VIM melting.

Higher levels of $\mathrm{O}_{2}$ just above the melt surface would result in alloy oxidation [1, 2]. This may indeed be the case, but since the slag products that tend to float on the melt surface due to their lower density are skimmed off before CLI-casting the mold, most of the oxide/nitride products do not enter the mold cavity. This procedure significantly reduces the pick up of oxides and/or nitrides. Insignificant change in the overall chemical composition compared to the starting composition (Table IV), and only a slight increase in O content, clearly shows that the argon atmosphere above the melt and in the mold cavity, and the ability to fill the mold with clean alloy from deep inside the molten pool are the major advantages of the CLI process, resulting in chemical composition comparable to the vacuum induction melted and vacuum cast product.

Inherent to the CLI process is the back and forth transport of several pounds of molten alloy through a relatively colder ceramic mold, when several molds are cast in succession. Loose shell materials and particles from the ceramic tube can enter the molten alloy and subsequently into the mold cavity. However, such ceramic oxides were not observed in the test bars either in FPI or X-ray inspection. Moreover, there was no evidence of such ceramic oxides on the fracture surfaces of the broken tensile test bars when examined using the SEM, as shown in Figure 4. The tensile and SR properties were also not adversely affected, as shown in Figures 2a) and 2b). Other data generated using the AMS 5383D specification also showed that CLI-cast IN718 test bars exceeded the tensile and the SR properties [9, 10]. These results indicate that the back and forth transport of several pounds of molten alloy through a relatively colder ceramic mold may introduce insignificant amounts of by-products into the alloy, but they do not adversely affect the tensile and stress rupture properties.

The RT and $1200{ }^{\circ} \mathrm{F}$ tensile properties, including ductility, were found to exceed the PWA 1469 specifications [3]. The PWA specification does not require a $1300{ }^{\circ} \mathrm{F}$ tensile test, but the test was carried out for information purposes. Results shown in Figure 2a) indicated that the $1300{ }^{\circ} \mathrm{F}$ test data exceeded the $1200{ }^{\circ} \mathrm{F}$ test specification. The LM parameter as reported in the literature [5] is shown in equation (2) below; this was comparable to the calculated parameter shown in equation (1).

$$
\mathrm{P}=0.001 \times \mathrm{T} \times(\log \mathrm{t}+25)
$$

Where $\mathrm{T}=$ test temperature in degrees Rankine $\left({ }^{\circ} \mathrm{R}={ }^{\circ} \mathrm{F}+460\right)$ and $\mathrm{t}=$ rupture time in hours.

These results show that the CLI melting and casting process does not adversely affect the IN718 alloy composition and its mechanical properties. 
Microstructure of all test bars examined was similar and comparable to each other. The typical grain size in the gage length $(0.5$ " diameter) of the bars ranged from 0.010 " to 0.060 " $(0.25 \mathrm{~mm}$ to $1.5 \mathrm{~mm})$. This is a very fine grain size for a typical investment cast IN718 product with a wall thickness of 0.5 ". A finer grain size generally results in improved yield strength as shown in Figure 2 [11]. The microstructure of the test bars consisted of the $(\mathrm{Nb}, \mathrm{Ti})$ rich carbides and borides less than 0.001 " (25 um) in length as shown in Figures 5 and 6. Such strengthening phases are typically observed in IN718 cast components [12]. Other defects that sometimes occur in castings, such as porosity and shrinkage, were not observed in the microstructure.

The (A1, Ti) oxide/Ti carbo-nitride particles observed in the microstructure, Figures 8 and 9, explain the slightly higher levels of $\mathrm{O}$ and $\mathrm{N}$ in the alloy (Table IV). These particles consisted of an Al oxide rich nucleus surrounded by Ti carbo-nitride indicating that the Al from the alloy first reacted with the $\mathrm{O}_{2}$ from the atmosphere, and formed a small particle. This Al oxide rich particle provided the nucleus for the formation and growth of the Ti carbo-nitride rich precipitate, which surrounded the Al oxide rich nucleus. The $\mathrm{Ti}$ in the alloy combined with $\mathrm{C}$ from the alloy and $\mathrm{N}$ from the atmosphere and formed the carbo-nitride. The size and shape of these particles was comparable to that of the $(\mathrm{Nb}, \mathrm{Ti})$ carbides/borides. They were randomly distributed within the microstructure. Clearly these particles did not adversely affect the tensile or the SR properties.

\section{Applications}

The CLI process is currently used in production to make components in IN713C, Haynes 230 and Nimonic 90 alloys. Shown below in Figure 10 are photographs of these components. Chemical composition, mechanical properties and the microstructure of these alloys routinely meet and exceed the customer specifications.
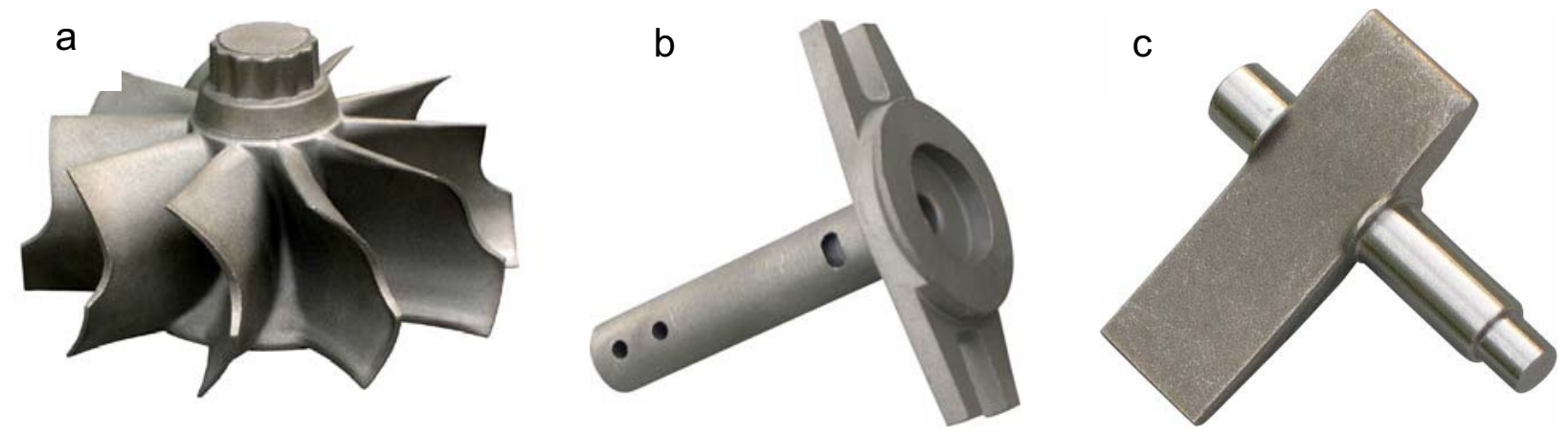

Figure 10: a) IN713C Turbocharger wheel 3.5" diameter, b) Haynes 230 high temperature probe 2.25" long, and c) Nimonic 90 turbocharger variable vane approximately 1.5 " long.

Typical chemical composition and RT tensile properties of Haynes 230 and Nimonic 90 are shown in Tables V and VI, respectively. Typically, La additions are made to the Haynes 230 pre-alloyed ingot bar stock during melting. In the case of Nimonic 90, charge materials containing desired elements are mixed in the crucible and melted.

Table V: Typical chemical composition of CLI-cast Haynes 230, Nimonic 90 and IN713 LC alloys.

\begin{tabular}{|l|c|c|c|c|c|c|c|c|c|c|c|c|}
\hline & $\mathrm{C}$ & $\mathrm{Cr}$ & $\mathrm{Co}$ & $\mathrm{Mo}$ & $\mathrm{W}$ & $\mathrm{Fe}$ & $\mathrm{Nb}$ & $\mathrm{Ti}$ & $\mathrm{B}$ & $\mathrm{Al}$ & $\mathrm{Si}$ & $\mathrm{La}$ \\
\hline Haynes 230 & 0.08 & 22 & 0.3 & 1.5 & 14 & 0.4 & & 0.03 & 0.004 & 0.35 & 0.3 & 0.04 \\
\hline Nimonic 90 & 0.02 & 19.2 & 18.3 & & & 0.8 & & 2.45 & & 1.55 & 0.85 & \\
\hline IN713 LC & 0.06 & 11.8 & & 4.1 & & & 1.9 & 0.67 & 0.007 & 5.9 & $<0.01$ & \\
\hline
\end{tabular}


Table VI: Typical RT tensile properties of CLI-cast Haynes 230, Nimonic 90 and IN713LC alloys.

\begin{tabular}{|l|c|c|c|c|}
\hline & UTS ksi & $0.2 \%$ YS ksi & E1 \% & RA \% \\
\hline Haynes 230 & 90 & 42 & 25 & 18 \\
\hline Nimonic 90 & 120 & 85 & 15 & 10 \\
\hline IN713 LC & 145 & 115 & 15 & 15 \\
\hline
\end{tabular}

Conclusions

A slightly higher level of oxygen up to $20 \mathrm{ppm}$ was observed in the 0.5 " dia x 4" long CLI-cast IN718 test bars, but no significant difference was observed in their overall composition as compared to the vacuum induction melted and vacuum cast starting alloy ingot. The slightly higher oxygen concentration, however, did not adversely affect the tensile test properties at both room temperature and at $1200{ }^{\circ} \mathrm{F}$, or the stress rupture properties. The Larson-Miller parameter calculated using the stress rupture data generated from the CLI-cast bars was of the form $\mathrm{P}=0.001 \times \mathrm{T} \times(\log \mathrm{t}+28)$, comparable to that reported in the literature for the vacuum induction melted and vacuum cast IN718 product.

The CLI investment casting process is a unique process used for melting and casting of superalloy components in an inert argon atmosphere. Ability to fill thin-wall components, lower alloy usage, ability to skim off the slag products from the melt surface combined with the ability to fill the molds from the bottom with a clean alloy taken from deep inside the melt surface, are some of the significant technical advantages of the CLI process that translate into higher throughput, while reducing the overall component cost. CLI casting of IN718 components for aerospace applications are in progress and components in IN713C, Haynes 230 and Nimonic 90 alloys are currently in production.

\section{References}

1. William R. Freeman. "Investment Casting", Superalloys II: High Temperature Materials for Aerospace and Industrial Power, ed. C. T. Sims, N. S. Stoloff and W. C. Hagel (New York, NY: John Wiley \& Sons, 1987) 387-439.

2. Gary L. Erickson. Metals Handbook, vol. 1, $10^{\text {th }}$ ed. (Metals Park, OH: American Society for Metals, 1990) 981-994.

3. Pratt \& Whitney P\&W Specification 1469 L - Nickel base Inconel 718, Vacuum Melted and CastHot Isostatically Pressed (East Hartford, CT 06108: January 1998).

4. Metals Handbook, vol. 1, $10^{\text {th }}$ ed. (Metals Park, OH: American Society for Metals, 1990) 627.

5. Howard R. Voorhees. Metals Handbook, vol. 8, $9^{\text {th }}$ ed. (Metals Park, OH: American Society for Metals, 1985) 329.

6. Matthew J. Donachie and Stephen J. Donachie, Superalloys a Technical Guide (Metals Park, OH: ASM International, 2002) 233-237.

7. Brown E. E and Donald R. Muzyka. "Nickel-Iron Alloys", Superalloys II: High Temperature Materials for Aerospace and Industrial Power, ed. C. T. Sims, N. S. Stoloff and W. C. Hagel (New York, NY: John Wiley \& Sons, 1987) 165-188.

8. Sanjay B. Shendye and Blair W. King, Private communication, Metal Casting Technology, Inc., March 17, 2005.

9. Aerospace Material Specification 5383D - Nickel Alloy, Corrosion and Heat Resistant, Investment Castings UNS N07718 (Warrendale, PA: SAE International, April 1993).

10. Blair W. King. Internal Report, Metal Casting Technology, Inc., February 2004. 
11. George E. Dieter, Mechanical Metallurgy, Third ed. (New York, NY: McGraw Hill Book Co., 1986). 189.

12. F. R. Morral, ed. Metals Handbook, vol. $3,9^{\text {th }}$ ed. (Metals Park, OH: American Society for Metals, 1980) 207-241. 